\title{
Towards the taxonomy of the Russian Murina (Vespertilionidae, Chiroptera)
}

\section{Sergei V. Kruskop}

\begin{abstract}
Specimens of the tube-nosed bats genus Murina, deposed in scientific collections of Moscow, Saint-Petersburg and Geneva were examined. Certain differences, mostly based on cranial measurements, were found between larger tube-nosed bats from Siberia and Far East, which give possibility to assign a subspecies rank to these forms. Valid name for the tube-nosed bats from Far East will be ognevi Bianchi, 1916, and for Siberian - sibirica Kastschenko, 1905. As the type of sibirica is absent in the residence mentioned in the original description and was not referred in scientific literature since the Kastschenko's publication, its neotype is designated here. Larger tube-nosed bats from Siberia and Far East are suggested to be treated as subspecies of Murina hilgendorfi; however the final elucidation of their relationships needs usage of the molecular analysis data. Lesser tube-nosed bats, Murina ussuriensis, are also represented in the Russian territory by the two forms. Bats from Sakhalin differ from mainland specimens and are describing here as a distinct subspecies. However interrelations between this form and lesser tube-nosed bats from Japan, as well as status of different Japanese populations, need further clarification.
\end{abstract}

KEY WORDS: Murina hilgendorfi, Murina ussuriensis, Southern Siberia, Far East, neotype, new subspecies.

Sergei V. Kruskop [kruskop@zmmu.msu.ru], Zoological Museum, Moscow State University, ul. Bolshaya Nikitskaya 6, Moscow 125009 Russia.

\section{О таксономии российских видов рода Murina (Vespertilionidae, Chiroptera)}

\section{С.В. Крускоп}

РЕЗЮМЕ. Исследованы экземпляры трубконосов рода Murina, хранящихся в научных коллекциях Москвы, Санкт-Петербурга и Женевы. Между большими трубконосами Сибири и Дальнего Востока существуют различия (в первую очередь в размерах черепа), позволяющие придать этим формам ранг подвидов. Действительным названием для больших трубконосов Дальнего Востока является ognevi Bianchi, 1916, а для сибирских — sibirica Kastschenko, 1905. Поскольку в указанном в первоописании месте хранения тип sibirica отсутствует, и упоминаний о нем в литературе нет, в данной работе выделен неотип этого таксона. Предложено считать больших трубконосов Сибири и Дальнего Востока подвидами Murina hilgendorfi, однако для окончательного выяснения их родственных связей необходимо использование молекулярных данных. Малые трубконосы, Murina ussuriensis, так же представлены на территории России двумя формами: трубконосы с Сахалина отличаются от материковых и описаны здесь как отдельный подвид. Однако его взаимоотношения с малыми трубконосами Японии (как и статус отдельных японских популяций) требует дальнейшего уточнения.

КЛЮЧЕВЫЕ СЛОВА: Murina hilgendorfi, Murina ussuriensis, Южная Сибирь, Дальний Восток, неотип, новый подвид.

\section{Introduction}

Inter- and infraspecific taxonomy of the tube-nosed bats from the genus Murina, as well as of the subfamily Murininae on the whole is known insufficiently. Poorness of the collection material together with the high number of the named forms defines the hardships of potential revisions. Few present attempts of such revisions are focused first of all on tropical members of the mentioned genus (e.g. Csorba \& Bates, 2005).

Southern Siberia and Russian Far East are covered with the northern extreme of the Murina distribution area. This is the reason not to expect high variability of tube-nosed bats on the Russian territory. Traditionally two species are accepted: larger one, namely Murina hilgendorfi Peters, 1880, occurring from Altai Mountains to Japan and Korea, and smaller one, Murina ussuriensis Ognev, 1913 which is restricted to the southern part of Russian Far East, Sakhalin, Kuril Islands and, probably, Korea (Simmons, 2005). The taxonomic status of both species was reconsidered several times.

Ognev accepted presence of the two larger species: Murina ognevi Bianchi, 1916 in Primor'e and M. leucogaster sibirica Kastschenko, 1905 in Southern Siberia 
(Ognev, 1928). Further both forms were suggested to be conspecific and considered to be partial synonyms of $M$. hilgendorfi or M. leucogaster Milne-Edwards, 1872 (Kuzyakin, 1950, 1965; Ellerman \& MorrisonScott, 1966; Wallin, 1969). Kuzyakin (1965) thought that this species has no infraspecific variability with the exception of presence of two "color phases". Ellerman and Morrison-Scott (1966) accepted both forms mentioned by Ognev as subspecies of $M$. leucogaster. Otherwise the name Murina leucogaster hilgendorfi was widely used for larger tube-nosed bats from Siberia and East Asia (Gromov et al., 1963; Wallin, 1969; Gromov \& Baranova, 1981; Krivosheev, 1984; Koopman, 1994). Latter author also included in the same form Murina fusca Sowerbi, 1922 from Manchuria. Yoshiyuki (1989) restricted distribution of $M$. hilgendorfi to Japan suggesting its specific distinction from $M$. leucogaster. She used name intermedius Mori, 1933 for the mainland form however not discussing its status. Appealing to this opinion, Tiunov (1997) and Botvinkin (2002) use the name sibirica treated it as a full subspecies of M. leucogaster. Simmons (in press) accepts full specific status of $M$. hilgendorfi and treats Siberian, Far East and Korean forms as synonyms.

Smaller species, which is much rarer in collections, was treated as Murina ussuriensis (Ognev, 1928; Pavlinov \& Rossolimo, 1987; Koopman, 1994) without any subspecies, or as partial (Wallin, 1969; Gromov \& Baranova, 1981; Krivosheev, 1984) or full synonym (Kuzyakin, 1965) of M. aurata Milne-Edwards, 1972. Tiunov (1997) suggested recognizing Japanese form $M$. silvatica Yoshiyuki, 1983 as a subspecies of $M$. ussuruiensis.

Studying of collection materials on Murina from Russia and East Asia, we came to a conclusion that taxonomy of both Russian species is more complex than it was traditionally thought. Larger tube-nosed bat from Russia is probably distinct from both M. leucogaster and $M$. hilgendorfi $\mathrm{s}$. str. and tentatively suggested to get the rank of separate subspecies of the latter species. Siberian and Far East populations of this species are well segregated mainly by the skull size. Sakhalin population of Murina ussuriensis must be considered as a separate subspecies, describing here.

\section{Material and methods}

Forty six specimens of tube-nosed bats from the Russian territory were investigated (only full-grown individuals of both sexes; dry or alcohol preserved skins with extracted skulls or alcohol preserved full carcasses; latter ones marked with *).

Murina bilgendorfi sibirica: Novosibirsk area - ZMMU-165891165893 (skulls only), 169308, 169309*, SDM-10221/540; Khakassiya - ZMMU-168257; Altai - ZMMU-113081*, Ros-36; Krasnoyarsk area - ZIN-16687 (skin only), ZIN-7560175604; Irkutsk area — ZIN-83995; Buryatiya - ZIN-85537;

M. bilgendorfi ognevi: Southern Primor'e - ZMMU-96364 ZMMU-173229, ZMMU-173231-173233, ZMMU-173235, ZMMU-173238-173240, ZMMU-173243-173246, ZMMU176137, ZMMU-176139*, ZIN-49734, SDM-10221/538 (skin only), Ros-15, Ros-77;
M. ussuriensis: Primor'e - ZMMU-96386, ZMMU-42508, ZMMU-173249, ZMMU-175399, ZIN-10849, ZIN-44102, SDM10221/536; Sakhalin - ZMMU-50955, ZMMU-175206175207; Kunashir — ZIN-72373*.

Also the following specimens of extralimital forms were taken for comparison: M. aurata - ZMMU-173401 (Vietnam, Lam Dong Province), M. cyclotis - MHNG-1926.033 (Laos), M. bilgendorfi s. str. - MHNG-1703.34 (Japan), M. buttoni ZMMU-167185 (Vietnam, Quang Binh Province), M. leucogaster - SDM-10221/537 (Central China), and M. silvatica MHNG-1703.33, ZIN-59106 (Japan).

The following 19 cranial measurements, followed by abbreviations in parentheses, were taken: condylocanine length (CCL), condylobasal length (CBL), mastoid width of the skull (MW), width of braincase (BCW), occipital height of the skull from occipital condyles to the occiput-parietal suture $(\mathrm{OH})$, width of postorbital constriction (POC), rostral width at the level of the infraorbital foramina (RW), rostral length from infraorbital foramen to the anterior margin of the upper jaw (RL), C-M3 length (CM), length of the upper canine cingulum base $(\mathrm{C})$, crown measured width between outer margins of upper canines (CC), crown measured width between outer margins of M3 (M3M3), length of the palate from the anterior margins of canines to the most posterior point of palate midline (Pal), width of the palate posterior to tooth rows (PalW), width of M3 (M3W), length of M3 (M3L), crown length of maxillary tooth row (cm3), lower jaw length from alveolus of i1 to the articulated process (MdL), lower jaw height to the tip of coronoid process $(\mathrm{MdH})$. Measurements were taken to the nearest $0.01 \mathrm{~mm}$ with digital calipers in combination with a binocular microscope.

Also some external measurements taken to the nearest $0.1 \mathrm{~mm}$ were used: forearm length, length of the first (claw) phalange of the first digit and ear length.

Skull measurements were processed with the use of Statistica for Windows 5.0 software. Measurements were standardizing to the dispersion to decrease the influence of size. Factor analysis (Principal Component method) was used for statistical treatment of the data.

Acronyms of depositories of the processed collections are using as follows: ZMMU - Zoological Museum of Moscow State University; SDM - State Darwin Museum, Moscow; ZIN - Zoological Institute of Russian Academy of Sciences, Saint Petersburg; MHNG - Natural History Museum of Geneva; Ros - personal collection of Valentina Rosina, Paleontological Institute of RAS.

\section{Taxonomy of larger Murina}

Siberian and Far East larger tube-nosed bats are well divided by the principal component analysis, based on 19 craniodental features, mainly by the first (PC I) and third (PC III) principal components (Fig. 1). PC I has high positive correlation with $\mathrm{MW}, \mathrm{RW}, \mathrm{CC}$ and $\mathrm{MM}$ - measurements, reflecting the width of the skull. PC III has high positive correlation with occiput height. In the space of these two components samples have no overlap, with the exception of one abnormally small (young?) specimen from Khassan District of Russian Far East. Discriminant function analysis also divides 


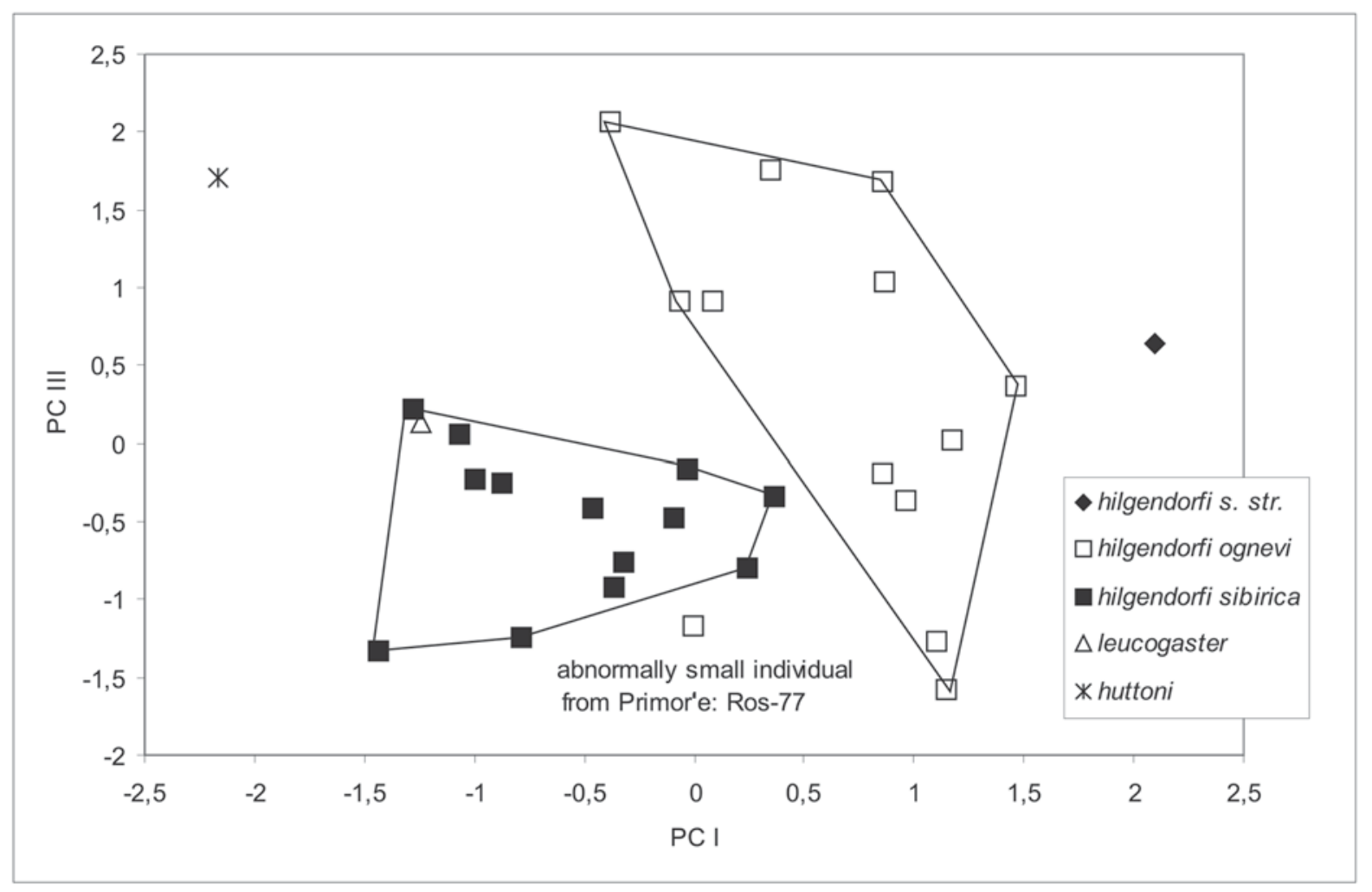

Figure 1. Scatterplot diagram for larger tube-nosed bats in the space of two principal components. PC I (eigenvalue 11.97; total variance $63.02 \%$ ) has major correlations with MW, RW, CC and MM; PC III (eigenvalue 2.51; total variance 13.22\%) mainly correlated with $\mathrm{OH}$ (see text for explanation of skull measurements).

these two forms with $100 \%$ posterior probabilities. Squared Mahalanobis distances from each specimen to their own group centroid and to the centroid of the other group were calculated as 2.72-13.37 and 43.17-83.06 for Far East specimens; 3.27-14.92 and 38.72-95.54 for Siberian individuals. This seems to bee a good argument for disruption of the given forms into different taxa.

Tube-nosed bats from Siberia and Far East differ significantly in skull size and proportions. In specimens from Southern Siberia skull is distinctly smaller then that of individuals from the Far East, demonstrating only very small overlap in CBL, CM and MdL (Tab. 1). Relatively small overlap we can observe in most of other craniodental features, with the exception of POC and PalW which are similar in both forms. External size in Siberian and Far East tube-nosed bats differ in the same way as cranial, but with wide overlapping: forearm length is $39.4 \pm 1.49(36.9-41.2) \mathrm{mm}$ in sibirica vs. $40.6 \pm 0.78(39.1-42.2) \mathrm{mm}$ in ognevi, $(\mathrm{n}=9$ and 16 , respectively). Both forms also have minor difference in pelage coloration and baculum shape.

Because of uncertainty of specific affiliation of the Russian larger tube-nosed bat, we try to compare it with similar forms from China and Japan. Unfortunately, we have had the very limited material on both, so our results on this field must be treated as preliminary.

Skulls of both Murina hilgendorfi from Japan and M. leucogaster from China differ from Russian individ- uals slightly larger, than Far East and Siberian bats from each other. However we could not found any "principal", qualitative difference in skull morphology. Also no difference was revealed in place of plagiopatagium attachment and shape of tragus. Despite the Ognev's description, both Siberian and Far East animals possess distal third of tragus slightly turned outwards, as well as M. leucogaster; the same feature was described for Indian individuals of the latter form (Bates \& Harrison, 1997).

More visible feature distinguishing Murina leucogaster from northern forms is pelage structure and coloration. In M. leucogaster main coloration is reddish-brown or pale red on back and almost white on belly. In the single available specimen from China back fur is less dense than in Russian individuals and has low contrast in coloration between underfur and hair tips (underfur is only slightly darker). Moreover, the same specimen possesses no bristle-like guard hairs, very characteristic for most of Murina. Also lower molars of the same Chinese specimen demonstrate hypoconulids more reduced than in Siberian and Far East individuals.

Murina hilgendorfis. str. may be distinguished from the Far East and Siberian forms by overall larger size and shorter pelage with somewhat different coloration (Yoshiuki, 1989). However, coloration pattern of the two studied individuals was more or less similar to that of Russian Murina, not exceeding difference between 
Table 1. Selected cranial measurements of the Russian Murina and some related species.

\begin{tabular}{|c|c|c|c|c|c|c|c|c|c|c|c|c|c|c|c|c|c|c|c|}
\hline & CCL & CBL & MW & $\mathrm{BCW}$ & $\mathrm{OH}$ & POC & RW & RL & $\mathrm{CC}$ & MM & $\mathrm{CM}$ & $\mathrm{C}$ & Pal & PalW & M3 W & M3L & $\mathrm{cm}$ & MdL & $\mathrm{MdH}$ \\
\hline \multicolumn{20}{|c|}{ Murina hilgendorfi s. str. $\mathrm{n}=1$} \\
\hline & 17.32 & 18.23 & 9.83 & 9.03 & 7.01 & 5.07 & 5.36 & 4.29 & 5.33 & 7.17 & 6.80 & 1.24 & 9.81 & 4.58 & 1.50 & 0.53 & 7.37 & 13.83 & 5.46 \\
\hline \multicolumn{20}{|c|}{ Murina hilgendorfi ognevi $\mathrm{n}=15$} \\
\hline mean & 16.73 & 17.51 & 9.33 & 8.73 & 6.45 & 4.97 & 4.88 & 3.78 & 4.92 & 6.51 & 6.16 & 1.06 & 9.11 & 3.89 & 1.44 & 0.52 & 6.71 & 13.20 & 5.17 \\
\hline $\min$ & 16.36 & 17.02 & 9.08 & 8.40 & 5.73 & 4.79 & 4.70 & 3.56 & 4.72 & 6.26 & 6.06 & 0.99 & 8.65 & 3.74 & 1.32 & 0.47 & 6.56 & 12.86 & 4.88 \\
\hline $\max$ & 17.15 & 17.90 & 9.79 & 9.08 & 6.96 & 5.30 & 5.12 & 4.21 & 5.24 & 6.73 & 6.40 & 1.12 & 9.59 & 4.20 & 1.63 & 0.57 & 6.97 & 13.66 & 5.53 \\
\hline SD & 0.24 & 0.27 & 0.20 & 0.18 & 0.43 & 0.15 & 0.14 & 0.21 & 0.14 & 0.13 & 0.09 & 0.04 & 0.25 & 0.13 & 0.08 & 0.03 & 0.12 & 0.24 & 0.17 \\
\hline \multicolumn{20}{|c|}{ Murina hilgendorfi sibirica $\mathrm{n}=13$} \\
\hline mean & 16.06 & 16.79 & 8.98 & 8.57 & 6.14 & 4.91 & 4.66 & 3.65 & 4.63 & 6.24 & 5.83 & 1.00 & 8.70 & 3.79 & 1.36 & 0.48 & 6.36 & 12.53 & 4.82 \\
\hline $\min$ & 15.34 & 15.96 & 8.63 & 8.18 & 5.48 & 4.59 & 4.44 & 3.38 & 4.38 & 5.77 & 5.64 & 0.94 & 8.45 & 3.46 & 1.24 & 0.44 & 6.03 & 11.88 & 4.43 \\
\hline $\max$ & 16.49 & 17.25 & 9.36 & 8.89 & 6.50 & 5.16 & 4.95 & 3.81 & 4.83 & 6.57 & 6.10 & 1.12 & 8.96 & 4.16 & 1.52 & 0.55 & 6.68 & 12.96 & 5.01 \\
\hline SD & 0.32 & 0.35 & 0.20 & 0.19 & 0.28 & 0.15 & 0.15 & 0.13 & 0.12 & 0.21 & 0.13 & 0.05 & 0.16 & 0.20 & 0.08 & 0.04 & 0.20 & 0.30 & 0.16 \\
\hline \multicolumn{20}{|c|}{ Murina leucogaster $\mathrm{n}=1$} \\
\hline & 16.61 & 17.43 & 8.88 & 8.58 & 6.32 & 5.41 & 4.84 & 3.97 & 4.67 & 6.22 & 6.35 & 1.13 & 9.14 & 3.96 & 1.47 & 0.56 & 6.77 & 13.21 & 5.33 \\
\hline \multicolumn{20}{|c|}{ Murina ussuriensis ussuriensis $\mathrm{n}=7$} \\
\hline mean & 13.62 & 14.19 & 7.45 & 7.41 & 5.40 & 4.37 & 4.08 & 3.36 & 3.57 & 5.18 & 5.01 & 0.77 & 7.19 & 3.39 & 1.14 & 0.47 & 5.43 & 10.31 & 3.68 \\
\hline $\min$ & 13.11 & 13.67 & 7.10 & 6.99 & 5.09 & 4.20 & 3.83 & 3.20 & 3.40 & 4.95 & 4.88 & 0.71 & 6.67 & 3.01 & 1.07 & 0.41 & 5.30 & 9.78 & 3.52 \\
\hline $\max$ & 13.89 & 14.51 & 7.67 & 7.65 & 5.64 & 4.60 & 4.26 & 3.59 & 3.82 & 5.43 & 5.16 & 0.81 & 7.44 & 3.57 & 1.19 & 0.53 & 5.54 & 10.64 & 3.93 \\
\hline SD & 0.27 & 0.29 & 0.20 & 0.24 & 0.23 & 0.16 & 0.18 & 0.13 & 0.15 & 0.17 & 0.10 & 0.04 & 0.27 & 0.20 & 0.04 & 0.04 & 0.08 & 0.30 & 0.14 \\
\hline \multicolumn{20}{|c|}{ Murina ussuriensis katerinae $\mathrm{n}=3$} \\
\hline & 13.33 & 13.82 & 7.26 & 7.1 & 5.71 & 4.28 & 3.82 & 3.16 & 3.57 & 5.04 & 4.80 & 0.76 & 7.18 & 3.48 & 1.08 & 0.38 & 5.29 & 10.1 & 3.72 \\
\hline & 13.15 & 13.6 & 7.25 & 7.03 & 5.52 & 4.15 & 3.88 & 2.92 & 3.37 & 5.14 & 4.73 & 0.67 & 7.23 & 3.41 & 1.13 & 0.41 & 5.19 & 10.1 & 3.52 \\
\hline & 13.3 & 13.84 & 7.22 & 7.07 & 5.35 & 4.12 & 3.75 & 3.06 & 3.46 & 5.16 & 5.09 & 0.80 & 6.64 & 3.39 & 1.17 & 0.42 & 5.55 & 9.96 & 3.5 \\
\hline mean & 13.26 & 13.75 & 7.24 & 7.07 & 5.53 & 4.18 & 3.82 & 3.05 & 3.47 & 5.11 & 4.87 & 0.74 & 7.02 & 3.43 & 1.13 & 0.40 & 5.34 & 10.05 & 3.58 \\
\hline \multicolumn{20}{|c|}{ Murina uss uriensis sylvatica $\mathrm{n}=2$} \\
\hline mean & 13.51 & 14.17 & 7.18 & 7.02 & 5.59 & 4.09 & 3.83 & 3.17 & 3.56 & 5.15 & 5.20 & 0.85 & 7.27 & 3.18 & 1.13 & 0.42 & 5.55 & 10.18 & 3.47 \\
\hline \multicolumn{20}{|c|}{ Murina aurata $\mathrm{n}=1$} \\
\hline & 12.34 & 13.02 & 7.42 & 7.21 & 5.81 & 4.09 & 4.12 & 3.13 & 3.39 & 4.88 & 4.68 & 0.70 & 6.37 & 3.10 & 1.11 & 0.42 & 5.13 & 9.31 & 3.32 \\
\hline
\end{tabular}

sibirica and ognevi. Both Russian and Japanese animals possess bristle-like guard hairs and relatively thick tail membrane hair cover. Difference in bacular shape is also insufficient and probably can disappear in more large series.

Taking into account all these factors, we can suggest treating sibirica and ognevi as two subspecies of Murina hilgendorfi and separating all these races from more southern Murina leucogaster. However the final clarification of this situation needs molecular studies.

\section{Murina hilgendorfi sibirica Kastschenko, 1905}

Harpiocephalus leucogaster sibiricus Kastschenko, 1905. Obzor mlecopitayushchih Zapadnoi Sibiri i Turkestana: 102b.

Type material. This form was described by Prof. N Kastschenko on the basis of single female, captured in 1900 in Kuznetskii Alatau Mountains. According to original description (Kastschenko, 1905), this specimen was kept in the collection of the Omsk museum. We got information that the mentioned specimen is absent in Omsk (information from the administration of the Omsk Regional Museum). We also did not found any mention about this specimen in scientific literature after Kastschenko's publication. So it can be supposed that the type of sibirica have been lost. This gives us a possibility to designate the neotype.

Neotype: ZMMU S-168257; adult female (in alcohol, skull extracted). Collected 27.05 .2000 by I.V. Karyakin in Khakassiya, in the vicinity of Malaya Syya, not far from original terra typica.

Description. Large tube-nosed bat with forearm length about $39.4 \mathrm{~mm}$ and condylobasal length of the skull $16.79 \pm 0.35 \mathrm{~mm}$. Skull relatively robust, with middle long rostrum and massive teeth. Upper rostral profile shallowly concaved. Brain case not inflated, rounded, with well-developed lambdoid and occipital crests; low sagittal crest present in frontal part of the skull roof and absent or obsolete posteriorly. Cochlear pits on the skull base well pronounced.

Teeth robust. Lower molars with merged entoconid and hypoconulid, as characteristic for many members 
of the genus (Rosina, 2003). Postcristid connected with hypoconulid part of this joint cusp. Upper molars without paraconule and hypocone. Last upper molar greatly reduced, amongst its structures only parastyle, preparacrista and paracone still exist. Second upper premolar, P4, without protocone. First upper premolar, P2, compressed between canine and the $\mathrm{P} 4$, length of its base is ca. two fifths of the second premolar. Outer upper incisor situated posterolaterally from the inner one and exceed it in crown area. Inner incisor is definitely bicuspid, posterior cusp somewhat lower than anterior; cusp of the outer incisor is intermediate in height between cusps of inner incisor. Both incisors not large, smaller than P2. Anterior edge of the canine cingulum is usually definitely higher than cingulum of outer incisor.

Fur is dense and long, up to $14 \mathrm{~mm}$ in length (guard hairs). Brownish-gray relatively pale curly underfur is about 4-5 mm long. Bases of guard hairs pale, but on the back and head distal third in most guard hairs is dark-brown. Silky bristle-like long hairs present on back and tail membrane. Fur cover is present on tail membrane, tibia, and posterio-proximal area of plagiopatagium; also sparse and short hairs cover the entire forearm up to the wrist.

Ear with rounded tip and shallow but definite notch on the posterior edge, ca. $16 \mathrm{~mm}$ in length $(\mathrm{n}=5)$. Tragus is narrow, sharply pointed, in contrast to Kastschenko's description. Its distal third is very slightly bent outward. Additional "odontoid projection" on its base, described by Kastschenko, usually not seen. Thumb long, with sharp long claw; its distal phalanx is ca. $9.6 \mathrm{~mm}$ in length $(\mathrm{n}=7)$. Wing membrane attaches to the basal phalanx of the outer toe. Tail tip projected beyond the posterior margin of the tail membrane on 3 $4 \mathrm{~mm}$.

Baculum is about $2 \mathrm{~mm}$, in general similar to that of hilgendorfi s. str. (Yoshiyuki, 1989) but with rounded distal end and notched basal end (Fig. 2A). Urethral groove wide but relatively shallow, dorsal side of the bone concaved.

Distribution. This form inhabits mountainous forested areas in southern Siberia, including Khakassiya, Altai Mountains, Sayan Mountains, and vicinity of Baikal. If Murina found in Mongolia and Kazakhstan, it can be represented by the same form.

\section{Murina hilgendorfi ognevi Bianchi, 1916}

Murina ognevi Bianchi, 1916. Ann. Zool. Mus. Acad. Sci., 21: 78

Type material. Holotype ZMMU S-96364; female (in alcohol, skull extracted, only mandible present). Collected by Palchevskyi (in "Types of vertebrates..." (2001) by mistake collector was marked as A. Tzerskyi) on Suchan River (now Partizanskaya), in the vicinity of Vladivostok.

Description. Largest Murina of the Asian mainland: forearm length ca. $40.6 \mathrm{~mm}$, condylobasal length of the skull $17.51 \pm 0.27 \mathrm{~mm}$. In general appearance similar to $M$. $h$. sibirica, with exception of larger overall size. Teeth structure also similar to that of sibirica, but cingulum of outer upper incisor is usually on the
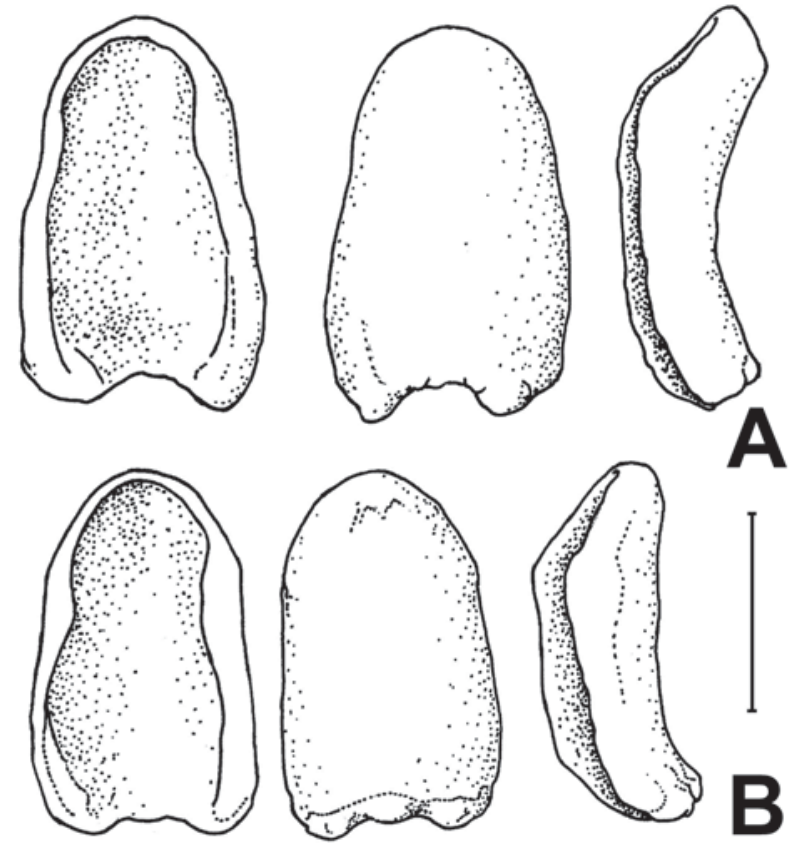

Figure 2. Baculum of adult Murina hilgendorfi; ventral, dorsal and lateral views. A - M. h. sibirica (ZMMU-169309), B - M. h. ognevi (ZMMU-176139).

same level as cingulum of canine or close to. Sagittal crest is usually extends through the skull roof from the frontal part to occipital crest; in its posterior half it can be reduced but still present.

Fur is dense and long, but slightly shorter than in sibirica, ca. 11-12 mm. Underfur looks more brownish. Most of guard hairs have pale tips; pale bases of these hairs are well defined (forming pale "belt" in the fur). On the whole fur looks less curly than in sibirica. Silky bristle-like long hairs present. Fur cover is present on tail membrane, tibia, posterio-proximal area of plagiopatagium; sparse and short hairs cover the entire forearm up to the wrist - as in sibirica.

Ears ca. $17.1 \mathrm{~mm}$ in length $(\mathrm{n}=11)$ and look more rounded than in sibirica, with less conspicuous emargination on posterior border (in some individuals this emargination may be virtually absent). Tragus is long, narrow and pointed. Small lobe at base in various individuals may be developed on the same level as in sibirica, reduced or virtually absent. Ognev (1928) pointed out that tragus of Murina ognevi is absolutely straight, in opposite to that of sibirica. Actually tragi of some individuals are strait while in other specimens they slightly bent outwards in distal third. However necessary to mention that in type specimen they are bent.

Baculum is about $1.8 \mathrm{~mm}$, similar to that of hilgendorfi s. str., but with less angular distal end. Notch at base less pronounced than in sibirica as well as dorsal concavity (Fig. 2B).

Distribution. Russian Far East including Sakhalin, also probably North-East China and Korea. Relations 


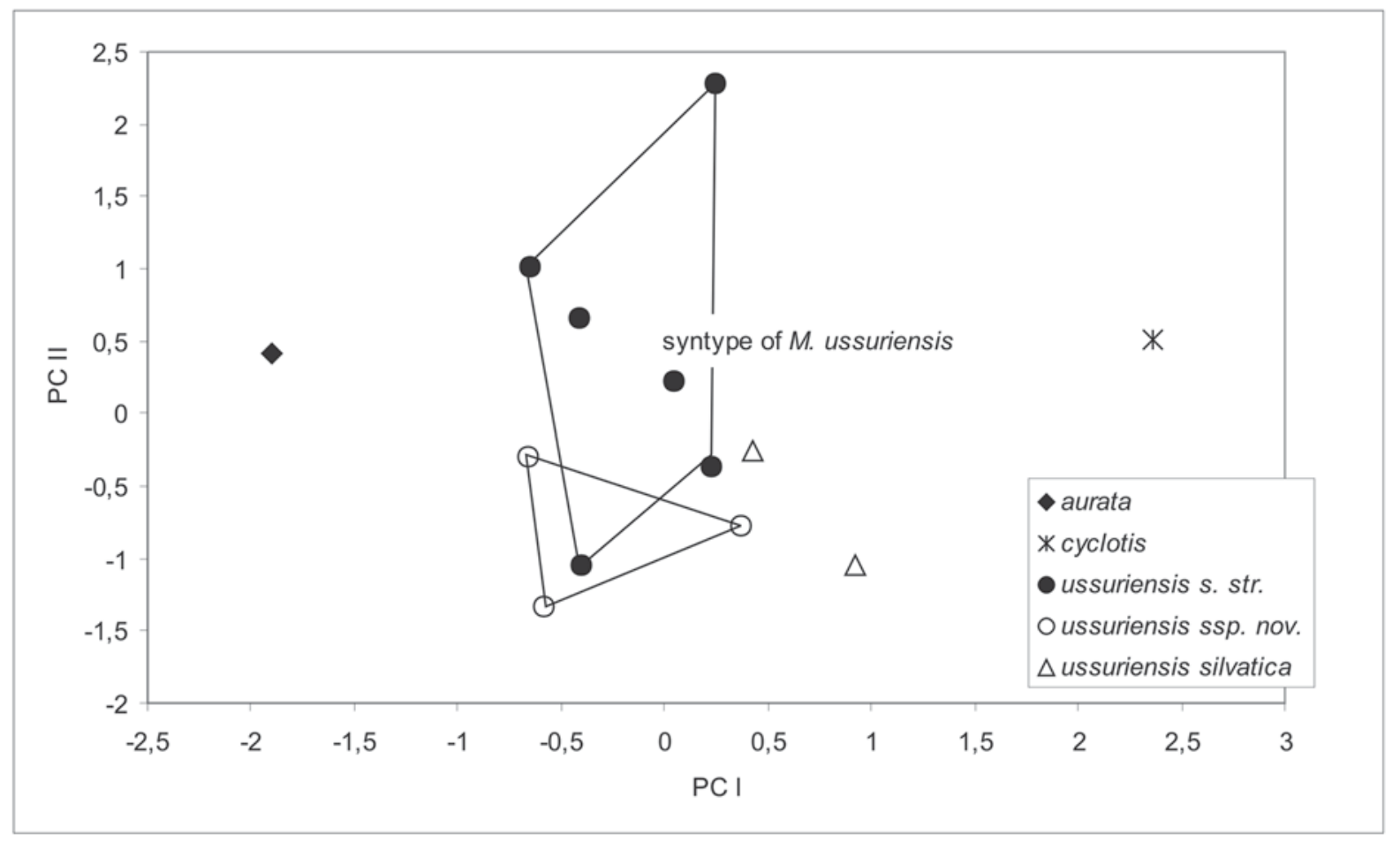

Figure 3. Scatterplot for small tube-nosed bat species in the space of two principal components. PC I (eigenvalue 11.48; total variance $60.41 \%$ ) has correlations with overall size, mainly with CCL, CBL, CC, MM, CM, C, Pal, CM and MdL; PC II (eigenvalue 2.46; total variance $12.92 \%$ ) has major correlation with RW.

with Murina fusca and M. l. intermedia need to be reassessed with the use of comparative material and molecular studies.

\section{Taxonomy of Murina ussuriensis}

Lesser tube-nosed bats from Sakhalin also possess some difference from M. ussuriensis s. str. In principal component analysis, based on cranial measurements, all the three specimens from Sakhalin are displaced in respect of mainland individuals by the second principal component (Fig. 3), which has greatest correlation with RW and M3L. Meantime, if we plot some concrete measurements, i.e. CBL against RW, the clouds will not overlap at all (Fig. 4). Samples differ in overall skull size: $\mathrm{CCl}$ and especially $\mathrm{CBL}$ and also RW demonstrate only small overlap; no overlap can be seen in RL. Meantime, some other measurements are more similar, for example CM3, canine length and width of the third molar. In smaller Sakhalin individuals $\mathrm{OH}$ is slightly larger on the average. Also this island race has proportionally wider posterior palate and more pronounced difference between MW and BCW. External size are comparable, mean forearm length in Sakhalin individuals is 29.7 vs. $29.8 \pm 1.42$ in M. ussuriensis s. str. ( $\mathrm{n}=3$ and 7, respectively). All these factors, together with some difference in pelage coloration, seem to be sufficient for supposition that the Sakhalin form belongs to a separate subspecies.
Japanese form silvatica traditionally treated as a separate species by Japanese authors (Yoshiyuki, 1989; Fukui et al., 2005) but probably belongs to Murina ussuriensis as a subspecies (Tiunov, 1997). It demonstrates some similarity with Sakhalin specimens e. g. in difference between MW and BCW and rostrum slightly shorter proportionally than in ussuriensis s. str. This form also has relatively high size variation (Fukui et al., 2005). Two measured individuals demonstrate size difference, comparable to that of between Sakhalin and mainland specimens of M. ussuriensis. So, it can be supposed that Sakhalin tube-nosed bats represent only a small race of $M$. ussuriensis silvatica.

Nevertheless, individuals from Sakhalin possess some difference from silvatica. They demonstrate overlap in CBL, CM, CC, MM and POC with most geographically close population of silvatica from Hokkaido (Fukui et al., 2005), but all their measurements are distinctly smaller than means of Hokkaido individuals. Both measured silvatica specimens have posterior palate narrower than in Sakhalin sample.

In the original description Yoshiyuki (1983) provide some qualitative features distinguishing $M$. silvatica and M. ussuriensis (necessary to mention, that Sakhalin specimens were also used for comparison): tragus strongly turned outwards; anterior narial emargination distinctly deeper than wide, extending to the posterior border of P2; P2 about 2/3 of P4 in height; anterior border of foramen magnum extending forwards 


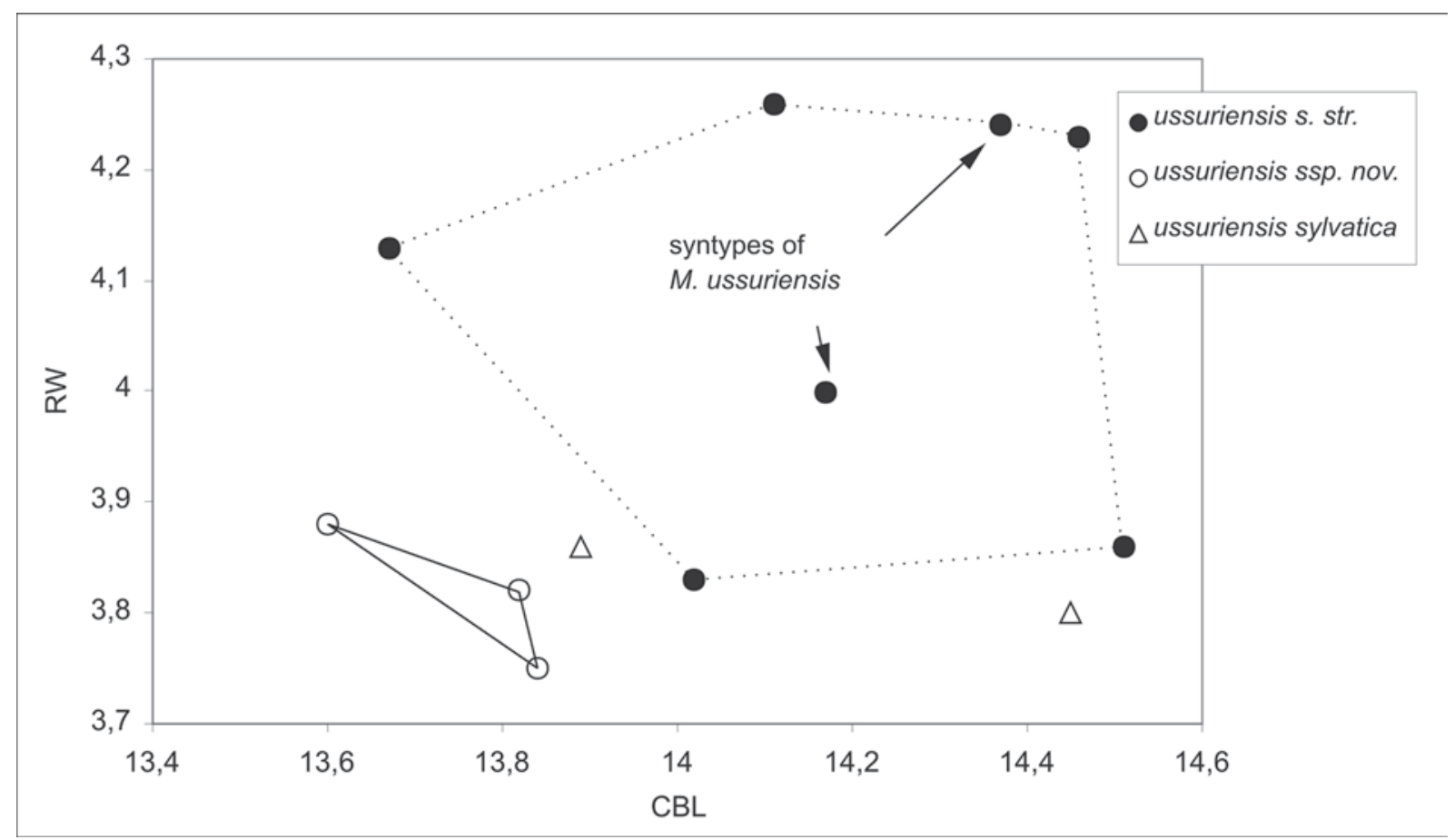

Figure 4. Scatterplot of two cranial measurements of Murina ussuriensis.

beyond the postero-inner corner of cochlea; fissure between cochlea and basioccipital always distinct; ears relatively long. Accordingly, the same features in $M$. ussuriensis (and also M. aurata) need to demonstrate the opposite stage.

Actually, tragus in all three Sakhalin individuals bent outwards more or less distinctly, while in $u s$ suriensis s. str. it is almost straight. Width of anterior narial emargination in all studied specimens of $u s$ suriensis is ca. $86-88 \%$ of its depth. Its posterior margin extends to the middle level of P2. In M. aurata this emargination has equal width and depth. Anterior palatal emargination in $M$. silvatica and $M$. ussuriensis barely extend beyond the middle level of canines; in $M$. aurata it is shorter and do not reach this level. In most seen specimens of $M$. ussuriensis $\mathrm{P} 2$ is about $2 / 3$ of $\mathrm{P} 4$ in height, as in silvatica, while in $M$. aurata it is not higher than $1 / 2$ of P4. Anterior border of foramen magnum extending forwards to the posterior level of cochlea or barely projected beyond this level in the mainland M. ussuriensis and in Sakhalin specimens and slightly more projected in M. aurata (however in all cases less than in the holotype of M. silvatica (Yoshiyuki, 1983)). Distinctiveness of the fissure between cochlea and basioccipital seems to be variable feature, depending also on quality of skull preparation; this fissure is well seen on one of three Sakhalin specimens. And at least ears of Sakhalin and mainland M. ussuriensis are distinctly shorter than that of measured specimens of $M$. silvatica and on the average shorter than that described for $M$. silvatica in particular from Hokkaido.

So, the Sakhalin specimens of the lesser tube-nosed bat demonstrate a sort of mixture features of the main- land and Japanese forms, meantime differentiating by small average sizes. It gives us possibility to recognize the Sakhalin population as a distinct taxon of the subspecific level. Meantime, difference between $M$. ussuriensis and M. silvatica to our opinion does not exceed subspecies level. On the opposite, M. aurata demonstrates some difference in qualitative features in skull and teeth proportions, which together with very distinct overall coloration pattern and fur coloration give possibility to treat it as a separate species.

\section{Murina ussuriensis katerinae subsp. nov.}

Type material. Holotype: ZMMU-175206, adult female (in alcohol, skull extracted). Collected on 26.06 .2003 by I.V. Gannitzkiy and Ya.A. Redkin on southern Sakhalin, Nevelsk District, Kitosia River.

Paratypes: ZMMU-50995 adult, sex unknown (dry skin and skull). Collected on 18.07.1947 by A. Gizenko on southern Sakhalin ("Aihama"); ZMMU-175207, adult female (in alcohol, skull extracted). Collectors, date and locality same as for the holotype.

Diagnosis. Very small tube-nosed bat: forearm length ca. 13.75, condylobasal length ca. $13.75 \mathrm{~mm}$. Similar to $M$. ussuriensis s. str. and $M$. u. silvatica. Differ from the first one in tragus shape, narrower brain case and somewhat richer coloration; from the second one - in shorter ears and foramen magnum less projecting forwards; from both in smaller size and proportionally wider posterior palate.

Description. Small tube-nosed bat with forearm length 28.9-30.6 mm. Weight of the holotype $5.6 \mathrm{~g}$. Tubular nostrils relatively short, projecting ca. $1 \mathrm{~mm}$ from base. Ear $12.1 \mathrm{~mm}$ in length, with wide rounded 
tip, its posterior border straight, without notch; distal third of ear pinna is slightly more pigmented than the rest of the ear (as in ussuriensis and silvatica). Tragus pointed, bent outwards at distal third, widest immediately above the anterior base, with well-developed posterior basal lobe. Fur dense and wooly. Wavy underfur is about 6-6.5 $\mathrm{mm}$ long (slightly longer than that of studied silvatica), with 3 to $3.5 \mathrm{~mm}$ dark brownish base. Guard hairs are up to $12 \mathrm{~mm}$ long, silky. They are relatively rich colored, reddish, in opposite to most of seen ussuriensis s. str., which have more dull and pale guard hairs. All the upper side of tail membrane, legs and adjacent parts of wing membranes are covered with more or less thick and long hairs. Dense cover of more short hairs also present on feet and thumbs, spreading up to the bases of claws, on forearms and proximal parts of second and fifth metacarpals. Hairs on the distal phalanxes of feet slightly extend over end of claws. Wing membrane attach to the base of the distal phalanx of outer toe.

Skull with rounded braincase which is narrower than mastoid width (while in ussuriensis s. str. it is more bulbous and almost equal to mastoid width). Posterior palate relatively wide, wider on the average than that of ussuriensis and silvatica. The rest of the skull similar to that of ussuriensis s. str. except smaller size. Anterior margin of foramen magnum barely extending forwards beyond the posterior level of cochlea. Cochlear pits are prominent and deep. Lambdoid crests well developed, but occipital crest is greatly reduced. Very small anterior sagittal crest is present on one specimen of three, temporal sagittal crest absent. Inner upper incisor bicuspid with reduced posterior cusp. Outer incisor situated latero-posterior to inner one; is makes up about three fifths of I2 height and five thirds of its crown area. First upper premolar (P2) is about two thirds of P4 in height and about one third in crown area. P4 without protocone. Upper molars without hypocone. Posterior upper molar possess reduced postparacrista and metastyle. On lower molars reduced hypoconulid is connected to entoconid, but less compressed to it in comparison to that of ussuriensis s. str. Postcristid is connected to hypoconulid.

Distribution. Southern Sakhalin. Specimen from Kunashir Island (ZIN-72373) tentatively belongs to the same form rather tan to silvatica because of shorter ear and longer fur.

Etymology. This form is named in honor of my colleague, a bat specialist Dr. Katerina A. Tsytsulina.

\section{Discussion}

Huge and still increasing amount of named forms within genus Murina may reflect the low migration activity of these bats, which on the next step increase role of various geographic barriers. Taking this fact into account, there is no great surprise in presence of four forms of this genus on the northern extreme of its distribution area. Large areas of Siberia and Far East together with high variability of natural environment on the one hand and isolation between mainland Primor'e and islands of the Pacific Ocean on the other generate enough conditions for appearing of distinct subspecies.

However the low number of collection materials still represent a problem during the investigations of real taxonomic status of these mentioned forms as well as many others. In the last years more or less acceptable series were collected for Murina hilgendorfi, while $M$. ussuriensis is represented by very few specimens. Collections used in this work give us representation about number of Murina species and subspecies in Russian fauna, but problems of relations between these forms and similar races which inhabit Manchuria, Korea and Japanese islands cannot be treated as finally solved. Bordering with distribution area of $M$. hilgendorfi ognevi, such race as intermedia and fusca may be distinct subspecies of the same species, subspecies of M. leucogaster, and junior synonyms of ognevi or distinct species. Murina ussuriensis silvatica is represented by at least four spatially separated populations (Fukui et al., 2005), which actually may be distinct subspecies or even belong to more than one species. In this case their interrelations with ussuriensis s. str. and katerinae ssp. nov. will need to be reassessed. Current view on the number of species and subspecies in Russian fauna and their relations with other forms, which follows from morphological data and actual for the present moment, need to be supported (or not) by further molecular investigations.

ACKNOWLEDGMENTS. I would like to express gratitude to Dr. Manuel Reudi, who's support gave me ability to visit Natural History Museum of Geneva and explore bat collections deposed there. I thank Dr. Alexandr O. Averianov, Dr. Petr P. Strelkov, Dr. Natalia I. Abramson and Galina I. Baranova for providing the possibility to use collections of Zoological Institution of RAS. My special thanks to Dr. Valentina V. Rosina who courtesy gave me her personal collection material for investigation.

\section{References}

Bates P.J.J. \& Harrison D.L. 1997. Bats of the Indian Subcontinent. Sevenoaks: Harrison Zoological Museum. 258 p.

Botvinkin A.D. 2002. [Bats in Pribaikal'e (Biology, Methods of Observation, Protection)]. Irkutsk: Vremya stranstvii. 208 p. [in Russian].

Csorba G. \& Bates P.J.J. 2005. Description of a new species of Murina from Cambodia (Chiroptera: Vespertilionidae: Murininae) // Acta Chiropterologica. Vol.7. No.1. P.1-8.

Ellerman J.R. \& Morrison-Scott T.C.S. 1951. Checklist of Palaearctic and Indian Mammals (1758 to 1946). London: Trustees of British Museum (Natural History). 810 p.

Fukui D., Maeda K., Hill D.A., Matsumura S. \& Agetsuma N. 2005. Geographic variation in cranial and external characters of the little tube-nosed bat, Murina silvatica in the Japanese archipelago // Acta Theriologica. Vol.50. No.3. P.309-322.

Gromov I.M., Gureev A.A., Novikov G.A., Sokolov I.I., 
Strelkov P.P. \& Chapskii K.K. 1963. [Mammals of the USSR Fauna. Part 1]. Moskva \& Leningrad: Izdatel'stvo Akademii Nauk SSSR. 639 p. [in Russian].

Gromov I.M. \& Baranova G.I. (eds.) 1981. [Catalogue of Mammals of the USSR. Pliocene-Recent]. Leningrad: Nauka. 456 p. [in Russian].

Kastschenko N.F. 1905. [Review of Mammals of the Western Siberia and Turkestan. Part 1. Chiroptera-Insectivora]. Tomsk. 107 p. [in Russian].

Koopman K.F. 1994. Chiroptera: Systematics // Handbook of zoology. Vol. 8. Mammalia, Pt. 60. New York: Walter de Gruyter. 217 p.

Krivosheev V.G. (ed.) 1984. [Terrestrial Mammals of the Far East of USSR. Identification Guide]. Moskva: Nauka. 358 p. [in Russian].

Kuzyakin A.P. 1950. [Bats]. Moskva: Sovetskaya Nauka. 442 p. [in Russian]

Kuzyakin A.P. 1965. [Order Chiroptera] // Bobrinskii N.A., Kuznetsov B.A. \& Kuzyakin A.P. [Identification Guide to the Mammals of the USSR. Second Edition]. Moskva: Prosveshchenie. 380 p. [in Russian].

Ognev S.I. 1928. [The Mammals of the Eastern Europe and the Northern Asia. Vol. I. Insectivores and Bats]. Mosk- va \& Leningrad: Glavnauka. 631 p. [in Russian]. Pavlinov I.Ya. \& Rossolimo O.L. 1987. [Systematic of Mammals of the USSR]. Moskva: Izdatel'stvo Moskovskogo Universiteta. 285 p. [in Russian].

Rosina V.V. 2003. [Murinodontia - special type of bat lower molars cusps structure] // Plecotus et al. No.6. P.36 [in Russian].

Simmons N.B. 2005. Order Chiroptera // Wilson D.E. \& Reeder D.M. (eds.). Mammal Species of the World: a Taxonomic and Geographic Reference. Third Edition. Baltimore: Johns Hopkins University Press. P.312-529.

Tiunov M.P. 1997. [Bats of Far East]. Vladivostok: Dal'nauka. 135 p. [in Russian].

Types of Vertebrates in the Zoological Museum of Moscow University. 2001. Moskva: Izdatel'stvo Moskovskogo Universiteta. $250 \mathrm{p}$.

Wallin L. 1969. The Japanese bat fauna // Zoologiska Bidrag från Uppsala. Vol.37. P.223-440.

Yoshiyuki M. 1983. A new species of Murina from Japan (Chiroptera, Vespertilionidae) // Bulletin of Natural Sciences Museum (Tokyo), Series A. No.9. P.141-150.

Yoshiyuki M. 1989. A Systematic Study of the Japanese Chiroptera. Tokyo: Natural Sciences Museum. 242 p. 